\title{
Effect of luting agent on the load to failure and accelerated-fatigue resistance of lithium disilicate laminate veneers
}

Gresnigt, Marco M M ; Özcan, Mutlu ; Carvalho, Marco ; Lazari, Priscilla ; Cune, Marco S ; Razavi, Peywand ; Magne, Pascal

\begin{abstract}
OBJECTIVE The aim of this study was to investigate the influence of the luting agent on the application of laminate veneers (LVs) in an accelerated fatigue and load-to-failure test after thermo-cyclic aging. METHODS Sound maxillary central incisors $(\mathrm{N}=40)$ were randomly divided into four groups to receive LVs (Li2Si2O5) that were adhesively bonded: Group CEMF: Adhesive cement (Variolink Esthetic LC), fatigue test; Group CEMLF: Adhesive cement, load-to-failure test; Group COMF: Resin composite (Enamel HFO), fatigue test; Group COMLF: Resin composite, load-to-failure test. The specimens were thermo-mechanically aged $(1.2 \times 106$ cycles at $1.7 \mathrm{~Hz} / 50 \mathrm{~N}, 8000$ cycles $\left.5-55^{\circ} \mathrm{C}\right)$ and then subjected to either accelerated fatigue $(5 \mathrm{~Hz}, 25 \mathrm{~N}$ increasing after each 500 cycles) or load to failure $(1 \mathrm{~mm} / \mathrm{min})$. Failure types were classified and data analyzed using chisquare, Kaplan Meier survival, Log Rank (Mantel-Cox) and independent-samples t-test. RESULTS After thermomechanical aging, fracture resistance $(\mathrm{p}<0.000)$ was higher in the composite groups. Kaplan Meier survival rates showed significant difference $(\mathrm{p}<0.001)$ between the composite (mean load: $1165 \mathrm{~N}$; mean cycles: 22.595$)$ and the cement groups (mean load: $762.5 \mathrm{~N}$; mean cycles: 14.569). The same differences were observed in the load to failure test (cement $\mathrm{M}=629.4 \mathrm{~N}, \mathrm{SD} \pm 212.82$ and composite $\mathrm{M}=927.59 \mathrm{~N}, \mathrm{SD} \pm 261.06$ ); $\mathrm{t}(18)=-2.80, \mathrm{p}=0.01$. Failure types were observed as fractures and chipping in group CEMF, all other groups were predominantly adhesive failures between the luting agent and the laminate veneer. SIGNIFICANCE The delivery of laminate veneers using a direct restorative composite rather than a resin cement resulted in significantly less chipping and fractures, higher fracture strength in both accelerated fatigue and load-to-failure.
\end{abstract}

DOI: https://doi.org/10.1016/j.dental.2017.09.010

Posted at the Zurich Open Repository and Archive, University of Zurich ZORA URL: https://doi.org/10.5167/uzh-146159

Journal Article

Accepted Version

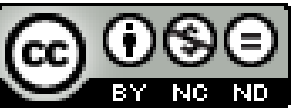

The following work is licensed under a Creative Commons: Attribution-NonCommercial-NoDerivatives 4.0 International (CC BY-NC-ND 4.0) License.

Originally published at:

Gresnigt, Marco M M; Özcan, Mutlu; Carvalho, Marco; Lazari, Priscilla; Cune, Marco S; Razavi, Peywand; Magne, Pascal (2017). Effect of luting agent on the load to failure and accelerated-fatigue resistance of lithium disilicate laminate veneers. Dental Materials, 33(12):1392-1401.

DOI: https://doi.org/10.1016/j.dental.2017.09.010 
Effect of cement type on the load to failure and micro-fatigue resistance of

lithium disilicate laminate veneers

\section{Marco M.M. Gresnigt, ${ }^{\mathrm{a},}{ }^{\star}$ Mutlu Özcan, ${ }^{\mathrm{b}}$ Marco Carvalho, ${ }^{\mathrm{c}}$ Priscilla Lazari, ${ }^{\mathrm{c}}$ Marco C.}

\section{Cune, ${ }^{\mathrm{a}}$}

\section{Peywand Razavi, ${ }^{a}$ Pascal Magne ${ }^{d}$}

aUniversity Medical Center Groningen, The University of Groningen, Groningen, Center for Dentistry and Oral Hygiene, Department of Fixed and Removable Prosthodontics, Groningen, The Netherlands

${ }^{b}$ University of Zurich, Dental Materials Unit, Center for Dental and Oral Medicine, Clinic for Fixed and Removable Prosthodontics and Dental Materials Science, Zurich,

Switzerland

'Piracicaba Dental School of the University of Campinas, Department of Prosthodontics and Periodontology, Piracicaba, Sao Paulo, Brazil

${ }^{d}$ Herman Ostrow School of Dentistry of USC, University of Southern California, Division of Primary Oral Health Care, Los Angeles, USA

Short title: Fatigue and load to failure tolerance of laminate veneers using cements and composite for luting

${ }^{*}$ Corresponding author:

Dr. Marco Gresnigt

Department of Fixed and Removable Prosthodontics

Center for Dentistry and Oral Hygiene

University Medical Center Groningen

The University of Groningen

Antonius Deusinglaan 1

9713 AV, Groningen

The Netherlands

Tel: +31-50-363-2608; fax: +31-50-363-2696

E-mail address: marcogresnigt@yahoo.com (M. Gresnigt) 


\section{ABSTRACT}

Objectives. Clinical survival of laminate veneer (LV) restorations does not rely on mechanical principles but on the adhesion of resin cements. The aim of this study was to investigate the influence of the cement type on the application of laminate veneers in a fatigue and maximum load to failure test after thermo-cyclic aging.

Methods. Window preparations were made in the enamel on the labial surfaces of sound maxillary central incisors $(\mathrm{N}=40)$ and they were randomly divided into four groups to receive LVs made of $\mathrm{Li}_{2} \mathrm{Si}_{2} \mathrm{O}_{5}$ that were adhesively bonded: Group CEMF: Adhesive cement (Variolink Esthetic LC), fatigue test; Group CEMLF: Adhesive cement, load to failure test; Group COMF: Resin composite (Enamel HFO), fatigue test; Group COMLF: Resin composite, load to failure test. All LVs were etched with $5 \% \mathrm{HF}$, cleaned and silanized. They were then cemented using adhesive resin cement (Variolink Esthetic LC) or resin composite (Enamel HFO). The specimens were thermo-mechanically aged $\left(1.2 \times 10^{6}\right.$ cycles, $1.7 \mathrm{~Hz}$, 8000 cycles, $\left.5-55^{\circ} \mathrm{C}\right)$ and then subjected to either fatigue $(5 \mathrm{~Hz}, 25 \mathrm{~N}$ increasing after each 500 cycles) or load to failure $(1 \mathrm{~mm} / \mathrm{min})$. Failure types and locations of debondings were classified. Data were statistically analyzed using chi-square, Kaplan Meier survival, Log Rank (Mantel-Cox) and independent-samples t-test.

Results. After thermo-mechanical aging, more incidence of fractures $(p<0.000)$ were seen in the cement groups than in the resin composite groups. Kaplan Meier survival rates showed significant difference $(p<0.001)$ for the composite (mean load: $1165 \mathrm{~N}$; mean cycles: 22.595$)$ and the cement groups (mean load: $762.5 \mathrm{~N}$; mean cycles: 14.569 ) in the accelerated fatigue test. Significant differences were also observed in the maximum load to failure test; cement $(M=629.4, S D=212,82)$ and composite $(M=927,59, S D=261,06) ; t(18)=-$ 2.80, $p=0.01$. Failure types were predominantly adhesive failures between the cement and the laminate veneer in groups 2, 3, 4 and fractures and chipping in group 1. 
Significance. Thermo-mechanical aging showed significantly less chipping and fractures in the composite groups. Cementation of laminate veneers using a direct composite, resulted in significantly higher fatigue and mean fracture strength.

Keywords: Adhesion; Bonding; Cementation; Ceramic; Fatigue; Fracture; Laminate; Veneer

\section{Introduction}

Laminate veneers (LV) are indicated as minimal invasive treatment options as an alternative to their full coverage crown counterpart in dentistry. Since retention of the LV restorations does not rely on mechanical principles, durable adhesive cementation of such restorations is crucial for long-term clinical success [1,2]. In clinical studies, survival rates of ceramic LVs range between 82 and $96 \%$ in 10 to 21 years [3-8]. Fractures of ceramic (5.6-11\%) and marginal defects (12-20\%) are often the main reasons of failure [3,4,8-12]. Successful cementation increases the retention, fracture resistance of the tooth and the restoration, and reduces the incidence of micro-leakage [2,13]. Adhesively bonded restorations offer the advantage of sealing the margins of the restorations, through which solubility of cements could be minimized. Also, adhesive cementation in bonded restorations do not only provide minimal invasive restorations but also reinforce the glassy matrix ceramics [1].

For the conditioning of glassy matrix ceramics, hydrofluoric acid (HF) etching followed by the application of a silane coupling agent is a well established method [14-17]. For the cementation of LVs, in most laboratory and clinical studies a photo-polymerized resin composite cement is suggested [2,5,8,18-21]. This kind of resin cement has some advantages over dual-polymerized ones. Photo-polymerized resin cements have better handling properties and it allows increased time to the clinician to fit the restoration. Furthermore, in some studies, with photo-polymerized resin materials increased bond strength was reported when compared to dual-polymerized resin cements [22-28]. In a 
study by Kameyama et al [23], a dual-polymerized resin cement was compared with a direct composite as a cement for ceramic inlays in a micro-tensile bond-strength test. The direct composite resulted in about $30 \mathrm{MPa}$ with only 1 pre-test failure whereas dualpolymerized resin composite cement delivered values below $10 \mathrm{MPa}$ and almost half of the specimens presented pre-test failures [23].

When testing durability of restorative materials in a laboratory setting, different aging methods are proposed. Besides different aging protocols such as water storage, thermocycling or thermo-mechanical aging, two different methods for fracture testing could be applied, namely load to failure test or the micro-fatigue test [29]. No consensus is available as to which method of durability test should be used to simulate the intra-oral situation ideally.

The objectives of this study were to a) compare two different cement materials, b) compare the outcome of the two different test methods on the survival of the different adhesively cemented laminate veneers. The following null-hypothesis were tested: a) aging would not have a significant effect on ceramic LVs cemented with two materials compared to direct resin composite LVs, b) different methods of cementation would not have an influence on the survival or strength, c) the test method would not have an influence on the strength values of the different LVs.

\section{Material and methods}

\subsection{Experimental groups and specimen preparation}

The brands, types, main chemical compositions, manufacturers and batch numbers of the

materials used for the experiments are listed in Table 1. Schematic description of the experimental design is presented in Fig. 1.

Sound human central incisors $(\mathrm{N}=40)$ of similar size, free of restorations and root canal treatment were selected from a pool of recently extracted teeth. All teeth were screened on 
the presence of cracks under ultraviolet light and those with cracks were eliminated and replaced with new teeth. The teeth were then randomly divided into 4 groups $(n=10)$.

CEMF: Ceramic LV, Photo-polymerizing cement, micro-fatigue test.

CEMLF: Ceramic LV, Photo-polymerizing cement, load to failure test.

COMF: Ceramic LV, Resin composite, micro-fatigue test.

COMLF: Ceramic LV, Resin composite, load to failure test.

Prior to the LV preparation, impressions were made using a high precision condensation silicone (Provil Novo putty fast set, Heraeus, Hanau, Germany) in order to obtain moulds for the provisional restorations. Window type of tooth preparations without incisal overlap were made under an optical microscope (Zeiss, OPMI pico, Oberkochen, Germany). After marking the outline with a marker, depth cuts of $0.3 \mathrm{~mm}$ were made $(801-014$, Komet, Besigheim Germany), preparations were finalized using a round-ended tapered diamond chamfer bur (879m-014 FG, Komet, Besigheim, Germany). The preparations ended completely in enamel, $1 \mathrm{~mm}$ above the cement-enamel junction. Smooth margins were created to prevent stress concentration zones using finishing discs (Sof-Lex Contouring and Polishing Discs, 3M ESPE, St Paul, Minnesota, USA). After preparations were finished and enamel surfaces were polished, impressions were made using an polyvinylsilicon impression material (Aquasil Ultra Heavy and XLV, Dentsply, Milford, USA) and these were checked for irregularities under an optical microscope (x10 magnification, Zeiss OPMI pico). Provisional LVs (Protemp 4, 3M ESPE, St Paul, Minnesota, USA) were made and applied using a spot etch technique where etching was performed for $10 \mathrm{~s}$ in the cervical and incisal part of the preparation. After adjusting the temporary restorations using polishing discs (Sof-Lex Countouring and Polishing Disks, 3M ESPE), specimens were stored in distilled water at $37^{\circ} \mathrm{C}$ for 2 weeks.

One dental technician fabricated all lithium disilicate $\left(\mathrm{Li}_{2} \mathrm{Si}_{2} \mathrm{O}_{5}\right)$ LVs (IPS e.max Press, Ivoclar Vivadent, Schaan, Liechtenstein) according to the instructions of the manufacturer. 
LVs were first sintered in a calibrated ceramic oven (Programat P3000, Ivoclar Vivadent), glazed and hand polished (CeraGlos HP, Edenta, Au, Switzerland). The final thickness of the laminate veneers was $0.3 \mathrm{~mm}$ at the incisal and $0.1 \mathrm{~mm}$ at the cervical regions.

\subsection{Adhesive cementation}

A photo-polymerizing resin cement (Variolink Esthetic LC, Ivoclar Vivadent) was used for group CEMF and CEMLF, and a resin composite (Enamel HFO, Micerium, Avegno, Italy) was used for group COMF and COMLF. Before cementation, provisional restorations were removed, teeth were cleaned with pumice and the fit of ceramic LVs were controlled under optical microscope (Zeiss OpmiPico, x25). LVs were then checked for fractures in the ceramic using ultraviolet light.

Cementation surfaces of the ceramic LVs were conditioned using hydrofluoric acid (Ceramic etching gel $<5 \%$ hydrofluoric acid, Ivoclar Vivadent) for $20 \mathrm{~s}$, rinsed and ultrasonically cleaned (Emag, Valkenswaard, The Netherlands) in distilled water for 5 minutes. They were then silanized (Monobond Plus, Ivoclar Vivadent) and heat dried at $100^{\circ} \mathrm{C}$ (DI500, Coltene, Altstatten, Switzerland) and coated with a thin layer of adhesive resin (Adhese Universal, Ivoclar Vivadent).

In all groups, enamel was etched with $38 \% \mathrm{H}_{3} \mathrm{PO}_{4}$ (Top Dent, DAB, Malmö, Sweden) for $30 \mathrm{~s}$ followed by $30 \mathrm{~s}$ of rinsing with copious water. Then, an adhesive resin (Adhese Universal, Ivoclar Vivadent) was applied, air-thinned but not photo-polymerized. While in groups CEMF and CEMLF a photo-polymerizing resin cement (Variolink Veneer, Ivoclar Vivadent) was used for cementation of the ceramic LVs, in group COMF and COMLF a pre-heated $\left(40^{\circ} \mathrm{C}\right.$, EASE-IT, Rønvig, Daugaard, Denmark) direct resin composite was used for the cementation of the laminate veneers. Cement or composite was applied at the intaglio surface of the LV and applied to their corresponding teeth under finger pressure until complete adaptation. 
Excess cement was removed using a dental probe and brush (GC, Leuven, Belgium). Glycerine gel (liquid strip, Ivoclar Vivadent) was applied at the margins of the LVs and photo-polymerized for $40 \mathrm{~s}$ from labial, lingual and incisal $\left(\geq 1000 \mathrm{~mW} / \mathrm{cm}^{2}\right.$, Bluephase, Ivoclar Vivadent) each. The output of the polymerization device was $1000 \mathrm{~mW} / \mathrm{cm}^{2}$ throughout the experiments (Bluephasemeter, Ivoclar Vivadent).

Cement interfaces at the margins were polished using rubber points (Astropol, Ivoclar Vivadent). The teeth with the cemented LVs were embedded perpendicularly in polymethylmethacrylate (Autoplast, Condular, Wager, Switzerland) up to the cementoenamel junction in the middle of the plastic rings (PVC, diameter: $2 \mathrm{~cm}$, height: $1 \mathrm{~cm}$ ).

\subsection{Aging, -fatigue and load to failure test}

After cementation, all specimens were artificially aged in a chewing simulator (SD Mechatronik CS-4.8 Chewing Simulator, Feldkirchen-Westerham, Germany) using a ceramic antagonist $(50 \mathrm{~N})$ at the incisal plane (Fig. 3a, 1.200 .000 cycles, $1.7 \mathrm{~Hz}$ ) and hydrolytically aged (8000 times in 5 to $55^{\circ} \mathrm{C}$ distilled water). Changes as chipping/fractures and incisal wear were evaluated. Digital photos of the specimens were made (Figs. 2,3) before and after aging.

Specimens in groups CEMF and COMF were subjected to accelerated fatigue using closed-loop servohydraulics (MiniBionix II MTS Systems, Eden Prairie, MN USA) with a flat surface composite cylinder (MZ100, 3M, St Paul, USA). Each specimen was placed in the load chamber with the load applied to the incisal edge in order to achieve simultaneous and equal contact of the loading surface. Ultrafine silicone carbide abrasive paper (600 grid, Norton Abrasives, Worcester, MA, USA) was used to flatten the incisal edge. The load chamber was filled with distilled water until complete immersion of the specimen. A frequency of $5 \mathrm{~Hz}$ was used starting at $50 \mathrm{~N}$ and gaining $25 \mathrm{~N}$ after each 500 cycles until catastrophic failure. The fracture load was noted as the machine stopped by a failure detection module. The number of cycles and maximum load were then recorded. 
The fracture test was performed on the specimens of groups CEMLF and COMLF in a Universal Testing Machine (810 Material Test System, MTS, Eden Prairie, USA) in a load to failure mode at a cross-head speed of $1 \mathrm{~mm} / \mathrm{min}$ with the load cell placed at the incisal edge (Fig. 3b). The maximum force to produce fracture was recorded in Newton.

\subsection{Microscopy analysis}

Failure types were evaluated using an optical microscope (Wild M3Z, Heerbrugg, Switzerland, x40). Additionally, after cleansing with alcohol, representative specimens from each group were first sputter-coated with a $3 \mathrm{~nm}$ thick layer of gold (80\%) / palladium (20\%) (90 s, 45mA; Balzers SCD 030, Balzers, Liechtenstein) and analyzed using cold

field emission Scanning Electron Microscope (SEM) (LyraTC, Tescan, Brno, Czech Republic). Images were made at $15 \mathrm{kV}$ at a magnification of x35 to x5.000.

\subsection{Statistical analysis}

A chi-square test of independence was performed to examine the relation between the cement type and mode of failure (wear or wear with fracture) after aging. The data of the accelerated fatigue were plotted in a Kaplan Meier survival curve to cycles and load. Additionally a Log Rank test (Mantel-Cox) was performed to compare survival curves. A Shapiro-Wilk's test ( $p>.05)$ and a visual inspection of their histogram, normal Q-Q plots and box plots showed that the data were approximately normally distributed for group CEMLF with a skewness of 0,581 (SE 0,687) and a kurtosis of 1,206 (SE 1,334) and group COMLF with a skewness of $-0,442$ (SE 0,687) and a kurtosis of $-0,206$ (SE 1,334). An independent-samples t-test was conducted afterwards to compare groups CEMLF and COMLF in terms of maximum load to failure using a statistical software programme (SPSS 22.0, SPSS inc., Chicago, USA).

\section{Results}

A chi-square test of independence was performed to examine the relation between the cement type and mode of failure (wear-wear with fracture) after thermocyclic aging. The 
relation between these variables was significant, $X 2(1, N=40)=22,56, p<0.000$ meaning that fractures $(n=18)$ were more frequently observed in the luting cement group 1 and 2; and the incidence of wear $(n=17)$ was higher in the resin composite groups (COMF and COMLF) after thermocyclic loading (Fig. 2).

In the accelerated fatigue test, mean survival rates for load were $762.5 \mathrm{~N}$ for group CEMF and $1165 \mathrm{~N}$ for group COMF. Log-rank test gives $\mathrm{X}^{2}(1, \mathrm{~N}=20)=10,98, \mathrm{p}<0.001$ indicating that the fracture loads for the LVs cemented with a resin composite was significantly higher than those cemented with resin composite cement. Mean survival rates for amount of cycles were 14.569 for group CEMF and 22.595 for group COMF $\left(X^{2}(1, N=20)=10,44\right.$, $p<0.001$, Log-rank test). The amount of cycles of the veneers cemented with a direct resin composite was significantly higher than the resin composite cement (Fig. 4).

An independent-samples t-test was conducted after normality test in order to compare groups CEMLF and COMLF in the load to failure test. There was a significant difference in the scores for group CEMLF $(M=629.4, S D=212.82)$ and group COMLF $(M=927.59$, $S D=261.06) ; t(18)=-2.80, p=0.01$ showing that cement type affected the results in maximum load to failure test (Fig. 5).

Failure types were predominantly adhesive between the resin cement and the LV in groups CEMF, COMF, COMLF while Group CEMLF presented chipping of the ceramic more frequently (Fig. 7). None of the teeth restored with LVs showed fractures of the root or large amount of tooth structure.

SEM images clearly showed chipping in group CEMLF (Fig. 8a) or detachment in groups CEMF and COMF (Figs. 8b-d) of the LV from the cement with some remnants of cement still attached on the tooth surface.

\section{Discussion}


The strength of LV restorations rely highly on the adhesion protocol used where surface conditioning of the ceramic and tooth substrates play a significant role [18]. Although adhesive cementation is well-established, failures are still experienced in clinical studies and survival rates are reported to range between 82 and $96 \%$ in 10 to 21 years [3-8]. Fractures of ceramic (5.6-11\%) and marginal defects (12-20\%) were the typical reasons for failure [3,4,6-12]. In addition to surface conditioning, resin cement can play an important role as seen in previous studies where there was a significantly positive effect of a direct composite as a cement in comparison to different dual-polymerized cements $[28,29]$. For this reason, this study was undertaken in order to compare photo-polymerizing resin composite to a direct composite as a luting material. Besides thermo-mechanically aging, two different test methods were used namely the accelerated fatigue and the wellestablished load to failure test. Based on the results of this study, since there were significant differences between the experimental groups in terms of aging, survival and fracture strengths, the hypothesis that the aging and cement type would have no effect could both be rejected. The hypothesis that testing set-up would deliver similar results could be accepted as both tests revealed similar significant differences between the test groups.

The ultimate load to test method for the assessment of cement effectiveness could be useful for ranking materials in in vitro settings. However, clinical performance of LVs is not only depended on the tested variables but also on the patient (teeth) factors, materials and operator factors [34,38]. Moreover, clinical studies are expensive and it is not ethical to test materials in patients without exposing them to preclinical tests. Therefore, laboratory aging and testing methods are applied in a manner to simulate the intra-oral situation as close as possible, focussing on one or two variables while excluding others. During function, dental materials are exposed to various conditions and material properties are changed due to degradation and aging [31]. Changes of materials are usually due to 
chemical breakdown by hydrolysis, stress induced effect associated with swelling and applied stress, leaching and corrosion [31]. A widely used aging method is thermo-cycling. The ISO TR 11450 indicates that thermocycling of 500 cycles in water between 5 and $55^{\circ} \mathrm{C}$ is an appropriate artificial aging test. However, in a review it was concluded that 10.000 cycles corresponds to 1 year of in vivo functioning [40]. Besides thermocyclic aging, mechanical loading could also have further aging effect on materials [31]. In mechanical aging, it is crucial to simulate the stress/load as close as possible to the in vivo situation [41]. In this study, load of the cyclic- as well as the fatigue- and load to failure test were performed on the incisal edge that clinically represents the end-to-end biting forces. Testing on the palatal side that is the most commonly used method requires application of the load cell on the palatal side. This would however eventually lead to testing the tooth strength and not the restoration-adhesive-tooth complex. In this study, significant differences were present between the two groups and more severe deterioration in the form of fractures and chippings were observed in the groups where ceramic LVs were cemented with a dual-polymerized cement.

Over the years, there has been growing interest in cementation of indirect restorations using highly filled resin composite by making them less viscous after preheating without detrimental changes to the properties of the material $[35,37,39]$. On the other hand, conventional resin composite luting cements have some advantages over a direct resin composite with their lower viscosity that allows easy control during positioning and fitting the restoration on the tooth substance. Based on the results of this study from both the fatigue as well as the load to failure tests, it could be stated that cementation by using a composite instead of a photo-polymerized resin composite cement would be beneficial. However, it should be noted the resin composite was pre-heated. LVs were placed under finger pressure but in the resin composite group, more pressure was practiced in order to 
remove the excess resin. Increasing thickness of the cement layer in especially very thin ceramic LVs could increase the strength [29].

Using micro-tensile adhesion tests, comparison was made between dual-polymerized resin cements and a direct resin composite but their adhesion was not compared for the application of LVs $[24,28]$. In a study by Sarr et al., direct resin composite using a regular bonding system resulted in higher microtensile bond strength to dentin when compared to the frequently used, etch and rinse, self-etch or self adhesive resin cements [24]. In this study, LVs were cemented to enamel but cohesive strength of the resin composite with 63 v\% fillers compared to dual-polymerized resin cement (38 $\mathrm{v} \%$ ) could have increased the strength of the tooth-cement-ceramic complex.

After surface conditioning of the ceramic with hydrofluoric acid etching and ultrasonic cleaning, silane coupling agent was applied optimizing the resin penetration and increased exposure of the silica to the silane in order to form siloxane bonds $[35,39,42]$. Heat treatment of the silane and thereby increased crosslinking, forming a uniform monolayer of silane molecules increases the adhesion of resin-based materials to ceramics [42]. Although optimal surface treatment was performed, most of the observed failures (58\%) after fatigue and load to failure tests were adhesive failures between the ceramic and the resin cement that indicates potential improvement in adhesion of such materials to ceramics. In this study, no fractures of the root or severe enamel/tooth fractures were observed. Such failures would be categorized as repairable ones and could be restored with resin composite chairside without necessitating renewal of the LV restoration.

\section{Conclusions}

From this study, the following could be concluded:

1. Luting of lithium disilicate laminate veneers using a direct resin composite resulted in significantly higher fatigue durability and maximum load to failure strengths. 
2. Both mechanical test methods used (fatigue vs load to failure) presented similar results indicating significant difference between the two different cementation methods.

3. Failure analysis after thermocyclic aging showed predominantly wear facettes together with chipping or fracture in laminate veneers that were bonded with resin cement while the groups of resin composite presented only wear.

\section{Acknowledgements}

The authors acknowledge Mr. Bernd vd Wal/ Rudy Caspers, of Laboratory Oosterwijk Dental/Elysee, UMCG, Groningen, The Netherlands, for their work in fabricating the

ceramic laminate veneers, and extend their gratitude to Ivoclar Vivadent, Schaan, Liechtenstein for their generous provision of some of the materials used in this study.

\section{Conflict of Interest}

The authors of this article certify that they have no proprietary, financial or other personal interest of any nature or kind in any product, service, and/or company that is presented in this article. 


\section{References}

[1] Addison O, Fleming GJP. The influence of cement lute, thermocycling and surface preparation on the strength of a porcelain laminate veneering material. Dent Mater 2004;20:286-92.

[2] Krämer N, Lohbauer U, Frankenberger R. Adhesive luting of indirect restorations. Am J Dent 2000;13:60D-76D.

[3] Friedman MJ. A 15-year review of porcelain veneer failure--a clinician's observations. Compend Contin Educ Dent 1998;19:625-8.

[4] Fradeani M, Redemagni M, Corrado M. Porcelain laminate veneers: 6- to 12-year clinical evaluation--a retrospective study. Int J Periodontics Restorative Dent 2005;25:9-17. [5] Peumans M, De Munck J, Fieuws S, Lambrechts P, Vanherle G, Van Meerbeek B. A prospective ten-year clinical trial of porcelain veneers. J Esthet Restor Dent 2006;18:1101.

[6] Beier US, Kapferer I, Burtscher D, Dumfahrt H. Clinical performance of porcelain laminate veneers for up to 20 years. Int J Prosthodont 2012;25:79-85.

[7] Gurel G, Morimoto S, Calamita M a, Coachman C, Sesma N. Clinical performance of porcelain laminate veneers: outcomes of the aesthetic pre-evaluative temporary (APT) technique. Int J Periodontics Restorative Dent 2012;32:625-35.

[8] Layton DM, Walton TR. The up to 21-year clinical outcome and survival of feldspathic porcelain veneers: accounting for clustering. Int J Prosthodont 2012;25:604-12.

[9] Dunne SM, Millar BJ. A longitudinal study of the clinical performance of porcelain veneers. Br Dent J 1993;175:317-21. 
[10] Shaini FJ, Shortall AC, Marquis PM. Clinical performance of porcelain laminate veneers. A retrospective evaluation over a period of 6.5 years. J Oral Rehabil $1997 ; 24: 553-9$.

[11] Dumfahrt H, Schäffer H. Porcelain laminate veneers. A retrospective evaluation after 1 to 10 years of service: Part II--Clinical results. Int J Prosthodont 2000;13:9-18.

[12] Guess PC, Stappert CFJ. Midterm results of a 5-year prospective clinical investigation of extended ceramic veneers. Dent Mater 2008;24:804-13.

[13] Kumbuloglu O, Lassila LVJ, User A, Toksavul S, Vallittu PK. Shear bond strength of composite resin cements to lithium disilicate ceramics. J Oral Rehabil 2005;32:128-33.

[14] Blatz MB, Sadan A, Kern M. Resin-ceramic bonding: A review of the literature. J Prosthet Dent 2003;89:268-74.

[15] Blatz MB, Sadan A, Maltezos C, Blatz U, Mercante D, Burgess JO. In vitro durability of the resin bond to feldspathic ceramics. Am J Dent 2004;17:169-72.

[16] Brentel AS, Özcan M, Valandro LF, Alarca LG, Amaral R, Bottino MA. Microtensile bond strength of a resin cement to feldpathic ceramic after different etching and silanization regimens in dry and aged conditions. Dent Mater 2007;23:1323-31.

[17] Neto DS, Naves LZ, Costa AR. The effect of hydrofluoric acid concentration on the bond strength and morphology of the surface and interface of glass ceramics to a resin cement 2015;40:470-9.

[18] Peumans M, Van Meerbeek B, Lambrechts P, Vanherle G. Porcelain veneers: a review of the literature. J Dent 2000;28:163-77.

[19] Gresnigt M, Özcan M, Kalk W. Esthetic rehabilitation of worn anterior teeth with thin porcelain laminate veneers. Eur J Esthet Dent 2011;6:298-313.

[20] Gresnigt MMM, Kalk W, Özcan M. Randomized controlled split-mouth clinical trial of direct laminate veneers with two micro-hybrid resin composites. J Dent 2012;40:766-75. 
[21] Gresnigt MMM, Kalk W, Özcan M. Clinical longevity of ceramic laminate veneers bonded to teeth with and without existing composite restorations up to 40 months. Clin Oral Investig 2013;17:823-32.

[22] Arrais CAG, Giannini M, Rueggeberg FA, Pashley DH. Effect of curing mode on microtensile bond strength to dentin of two dual-cured adhesive systems in combination with resin luting cements for indirect restorations. Oper Dent 2007;32:37-44.

[23] Frankenberger R, Reinelt C, Petschelt A, Krämer N. Operator vs. material influence on clinical outcome of bonded ceramic inlays. Dent Mater 2009;25:960-8.

[24] Sarr M, Kane AW, Vreven J, Mine A, Van Landuyt KL, Peumans M, et al. Microtensile bond strength and interfacial characterization of 11 contemporary adhesives bonded to bur-cut dentin. Oper Dent 2010;35:94-104.

[25] Gregor L, Bouillaguet S, Onisor I, Ardu S, Krejci I, Rocca GT. Microhardness of lightand dual-polymerizable luting resins polymerized through 7.5-mm-thick endocrowns. J Prosthet Dent 2014;112:942-8.

[26] Lührs AK, Pongprueksa P, De Munck J, Geurtsen W, Van Meerbeek B. Curing mode affects bond strength of adhesively luted composite CAD/CAM restorations to dentin. Dent Mater 2014;30:281-91.

[27] Lührs AK, De Munck J, Geurtsen W, Van Meerbeek B. Composite cements benefit from light-curing. Dent Mater 2014;30:292-301.

[28] Kameyama A, Bonroy K, Elsen C, Lührs AK, Suyama Y, Peumans M, et al. Luting of CAD/CAM ceramic inlays: Direct composite versus dual-cure luting cement. Biomed Mater Eng 2015;25:279-88.

[29] Krejci I, Mueller E, Lutz F. Effects of thermocycling and occlusal force on adhesive composite crowns. J Dent Res 1994;73:1228-32.

[30] Gale MS, Darvell BW. Thermal cycling procedures for laboratory testing of dental restorations. J Dent 1999;27:89-99. 
[31] Magne P, Versluis A, Douglas WH. Effect of luting composite shrinkage and thermal loads on the stress distribution in porcelain laminate veneers. J Prosthet Dent 1999;81:335-44.

[32] Frankenberger R, Petschelt A, Krämer N. Leucite-reinforced glass ceramic inlays and onlays after six years: clinical behavior. Oper Dent 2000;25:459-65.

[33] Magne P, Perroud R, Hodges JS, Belser UC. Clinical performance of novel-design porcelain veneers for the recovery of coronal volume and length. Int $\mathrm{J}$ Periodontics Restorative Dent 2000;20:440-57.

[34] Canay S, Hersek N, Ertan A. Effect of different acid treatments on a porcelain surface. J Oral Rehabil 2001;28:95-101.

[35] Magne P, Cascione D. Influence of post-etching cleaning and connecting porcelain on the microtensile bond strength of composite resin to feldspathic porcelain. J Prosthet Dent 2006;96:354-61.

[36] Drummond JL. Degradation, fatigue, and failure of resin dental composite materials. J Dent Res 2008;87:710-9.

[37] Vailati F, Belser UC. Full-mouth adhesive rehabilitation of a severely eroded dentition: the three-step technique. Part 1. Eur J Esthet Dent 2008;3:30-44.

[38] Demunck J, Van Landuyt K, Peumans M, Poitevin A, Lambrechts P, Braem M, et al. A critical review of the durability of adhesion to tooth tissue: Methods and results. J Esthet Restor Dent 2010;22:72-3.

[39] Lucey S, Lynch CD, Ray NJ, Burke FM, Hannigan A. Effect of pre-heating on the viscosity and microhardness of a resin composite. J Oral Rehabil 2010;37:278-82.

[40] Martins ME, Leite FP, Queiroz JR, Vanderlei AD, Reskalla HN, Özcan M. Does the ultrasonic cleaning medium affect the adhesion of resin cement to feldspathic ceramic? J Adhes Dent 2012;14:507-9. 
[41] Corazza PH, Cavalcanti SCM, Queiroz JRC, Bottino MA, Valandro LF. Effect of postsilanization heat treatments of silanized feldspathic ceramic on adhesion to resin cement. J Adhes Dent 2013;15:473-9

[42] van den Breemer CRG, Gresnigt MMM, Cune MS. Cementation of glass-ceramic posterior restorations: a systematic review. Biomed Res Int 2015;2015:148954. 


\section{Captions to tables and figures:}

\section{Tables:}

Table 1. The brands, types, chemical compositions, manufacturers and batch numbers of the materials used for the experiments.

\section{Figures:}

Fig. 1. Flow-chart showing experimental sequence and allocation of groups.

Figs. 2a-b. a) Representative specimens from groups a) CEMF after aging, note the fracture/chipping at the incisal edge, b) COMF, note the wear of the ceramic at the incisal edge.

Figs. 3a-b. The position of the load cell a) in the accelerated micro-fatigue device and b) during maximum load to failure test, in relation to the laminate veneer-tooth interface.

Figs. 4a-b. Survival functions in relation to a) the amount of cycles and b) load of the micro-fatigue test for group CEMF: Variolink Veneer and group COMF: Micerium HFO.

Fig. 5. Boxplot of the maximum load to failure data of groups CEMLF and COMLF.

Fig. 6. Frequencies of failure modes in percentages. Type I: Cohesive ceramic fracture; Type II: Chipping of the ceramic <1/3; Type III: Chipping of the ceramic >1/3; Type IV: Adhesive failure between cement and ceramic; Type V: Adhesive between cement and enamel; Type VI: Tooth fracture.

Figs. 7a-d. Typical failure types from a) a specimen in Group CEMLF where a chipping occurred in $>1 / 3$ of the laminate veneer, b) a specimen from group CEMF where delamination occurred between the ceramic and resin cement, c) a specimen from group COMF where an adhesive failure occurred between the resin cement and enamel, d) the corresponding SEM image (x 2500) of group COMF of the enamel $(E)$ and resin composite (C) 
Tables:

\begin{tabular}{|c|c|c|c|c|}
\hline Brand & Type & Chemical Composition & Manufacturer & Batch Number \\
\hline Top Dent & Etching agent & 38\% Phosphoric acid & $\begin{array}{l}\text { DAB, Malmö, } \\
\text { Sweden }\end{array}$ & $\begin{array}{l}140919, \\
140128,14103\end{array}$ \\
\hline $\begin{array}{l}\text { Universal } \\
\text { Adhesive }\end{array}$ & Universal Adhesive & $\begin{array}{l}\text { 2-hydroxyethyl methacrylate, Bis- } \\
\text { GMA, ethanol, 1,10-decandiol } \\
\text { dimethacrylate, methacrylated } \\
\text { phosphoric acid ester, } \\
\text { campherquinone, 2- } \\
\text { dimethylaminoethyl methacrylate, } \\
\text { ethanol }\end{array}$ & $\begin{array}{l}\text { Ivoclar Vivadent, } \\
\text { Schaan, } \\
\text { Liechtenstein }\end{array}$ & T28040 \\
\hline $\begin{array}{l}\text { IPS Empress } \\
\text { etching gel }\end{array}$ & Ceramic etching ge & $<5 \%$ Hydrofluoric acid & Ivoclar Vivadent & T34823 \\
\hline Monobond Plus & $\begin{array}{l}\text { Silane coupling } \\
\text { agent }\end{array}$ & $\begin{array}{l}\text { Ethanol, 3-trimetho- } \\
\text { xysilsylpropylmethacrylaat, } \\
\text { methacrylated phosphoric acid ester }\end{array}$ & Ivoclar Vivadent & T21454 \\
\hline $\begin{array}{l}\text { Enamel Plus } \\
\text { HFO }\end{array}$ & $\begin{array}{l}\text { Photo-polymerized } \\
\text { resin composite }\end{array}$ & $\begin{array}{l}\text { 1,4-Butandioldimethacrylate, } \\
\text { urethandimethacrylate, } \\
\text { Diurethandimethacrylate, Iso- } \\
\text { propyliden-bis (2(3)-hydroxy-3(2)- } \\
4(\text { phenoxy)propyl)-bis(methacrylate), } \\
\text { glass filler: mean particle size } 0.7 \mu \mathrm{m} \\
\text { highly dispersed silicone dioxide }\end{array}$ & $\begin{array}{l}\text { Micerium, Avegno, } \\
\text { Italy }\end{array}$ & 2014004869 \\
\hline $\begin{array}{l}\text { Variolink } \\
\text { Esthetic LC }\end{array}$ & $\begin{array}{l}\text { Dual-polymerized } \\
\text { resin cement }\end{array}$ & $\begin{array}{l}\text { Urethane dimethacrylate, ytterbium } \\
\text { trifluoride, 1,10-decandiol } \\
\text { dimethacrylate, glycerine-1.3- } \\
\text { dimethacrylate, 2,6-di-tert-butyl-p- } \\
\text { cresol }\end{array}$ & Ivoclar Vivadent & T21748 \\
\hline
\end{tabular}

Table 1. The brands, types, chemical compositions, manufacturers and batch numbers of the materials used for the experiments. 
Figures:

\begin{tabular}{|c|c|c|c|}
\hline & \multicolumn{2}{|c|}{ Experimental Sequence } & \\
\hline & \multicolumn{3}{|c|}{ Maxillary Central Incisors $(\mathrm{N}=40, \mathrm{n}=10$ per group } \\
\hline \multicolumn{2}{|c|}{ Resin Composite Cement } & \multicolumn{2}{|c|}{ Direct Resin Composite } \\
\hline CEMF & CEMLF & COMF & COMLF \\
\hline \multicolumn{4}{|c|}{ Laminate veneer window preparation + Impression + Provisional (2 weeks) } \\
\hline \multicolumn{2}{|c|}{$\begin{array}{l}\text { Cleaning (pumice) } \\
\text { Etch + adhesive } \\
\text { Application of Cement (Variolink Esthetic) } \\
\text { Adaptation of veneer on tooth }\end{array}$} & \multicolumn{2}{|c|}{$\begin{array}{l}\text { Cleaning (pumice) } \\
\text { Etch + adhesive } \\
\text { Application of Composite (HFO Enamel) } \\
\text { Adaptation of veneer on tooth }\end{array}$} \\
\hline \multicolumn{4}{|c|}{ Photo polymerization of $40 \mathrm{~s}$ per side + Finishing and Polishing } \\
\hline \multicolumn{4}{|c|}{ Thermo-Mechanically aging $\left(1.2 \times 10^{6}\right.$ cycles, $1.7 \mathrm{~Hz}, 8000$ cycles, $\left.5-55^{\circ} \mathrm{C}\right)$} \\
\hline $\begin{array}{c}\text { Micro-fatigue } \\
\text { (5 Hz, 50N each } \\
500 \text { cycles) }\end{array}$ & Load to Failure & $\begin{array}{c}\text { Micro-fatigue } \\
\text { (5 Hz, 50N each } \\
500 \text { cycles) }\end{array}$ & Load to Failure \\
\hline
\end{tabular}

Fig. 1. Flow-chart showing experimental sequence and allocation of groups.
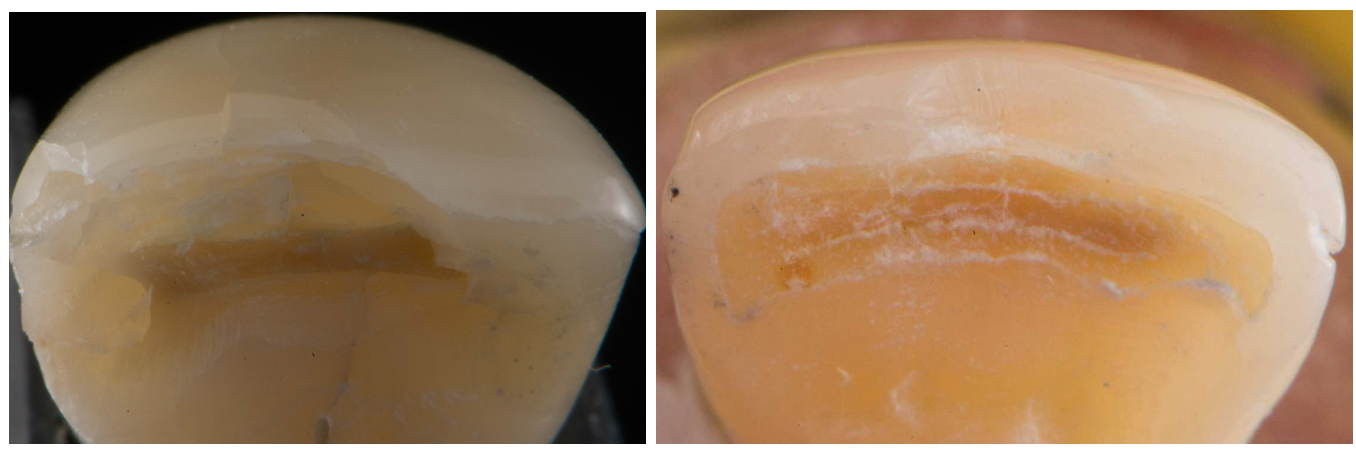

Figs. 2a-b. a) Representative specimens from groups a) CEMF after aging, note the fracture/chipping at the incisal edge, b) COMF, note the wear of the ceramic at the incisal edge. 


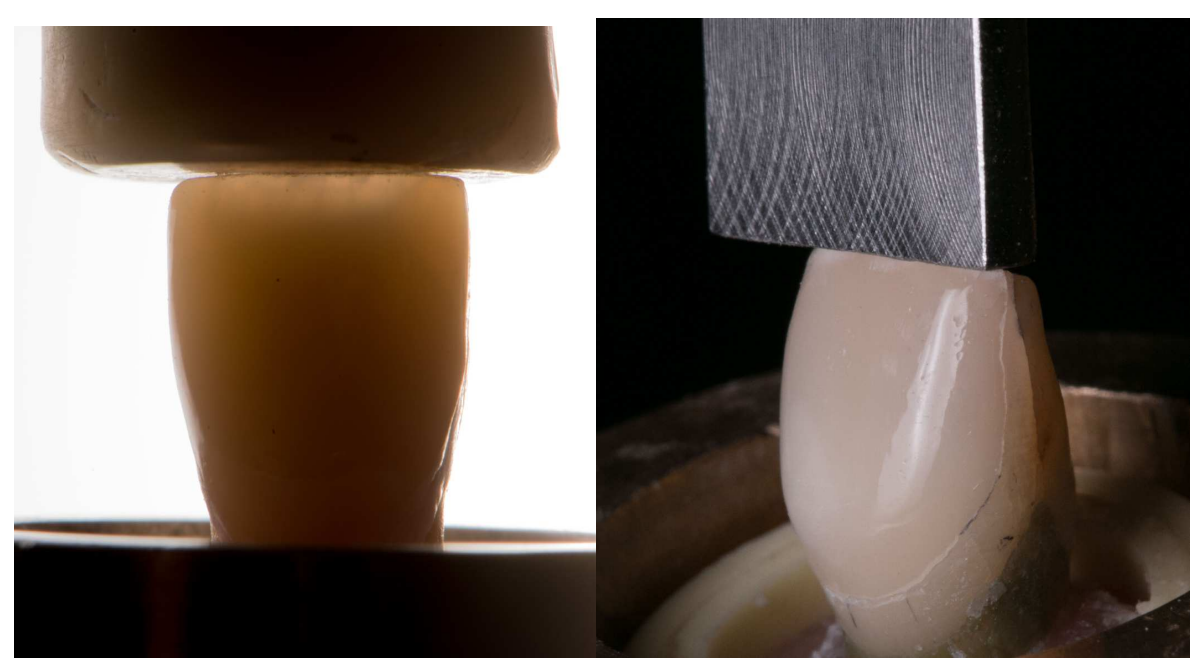

Figs. 3a-b. The position of the load cell a) in the accelerated micro-fatigue device and $\mathbf{b}$ ) during maximum load to failure test, in relation to the laminate veneer-tooth interface.
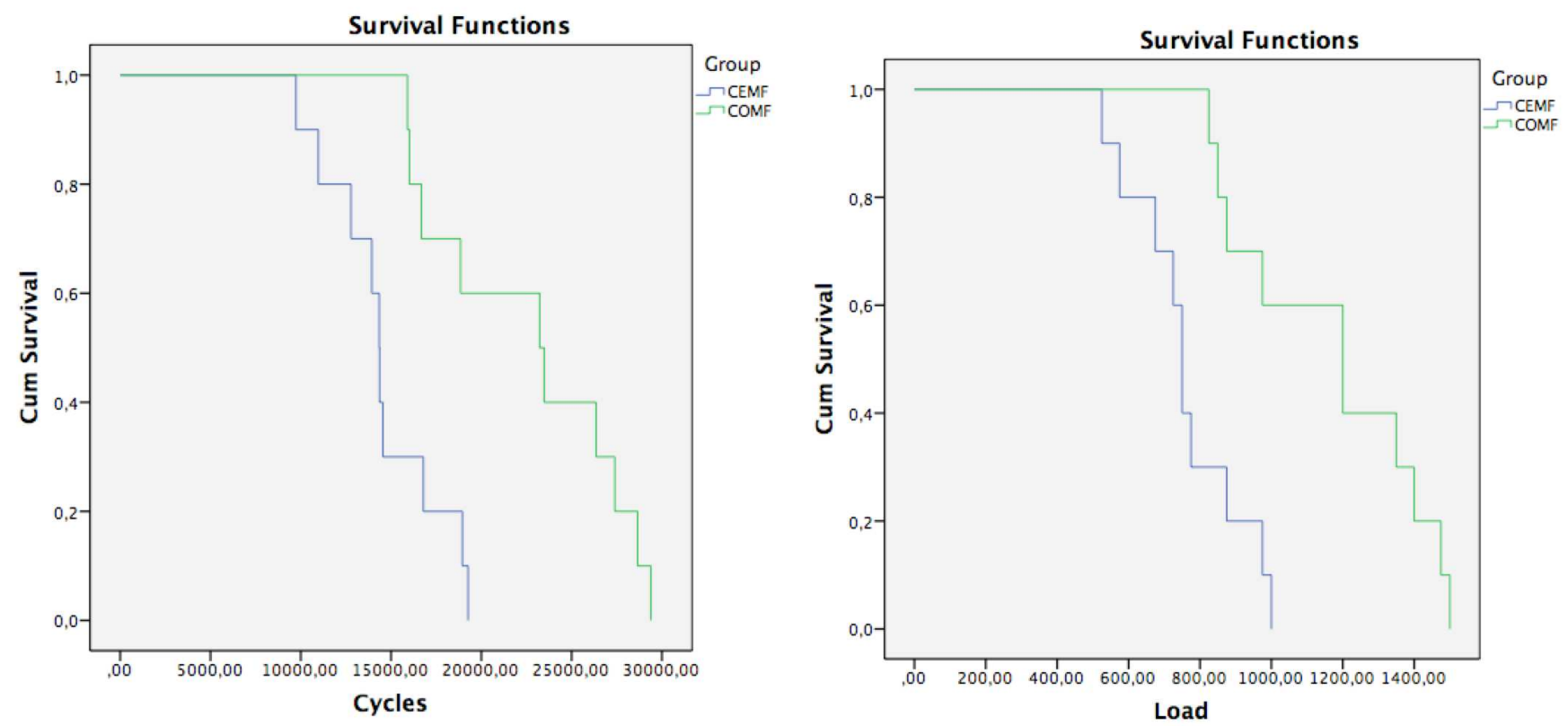

Figs. 4a-b. Survival functions in relation to a) the amount of cycles and b) load of the micro-fatigue test for group CEMF: Variolink Veneer and group COMF: Micerium HFO. 


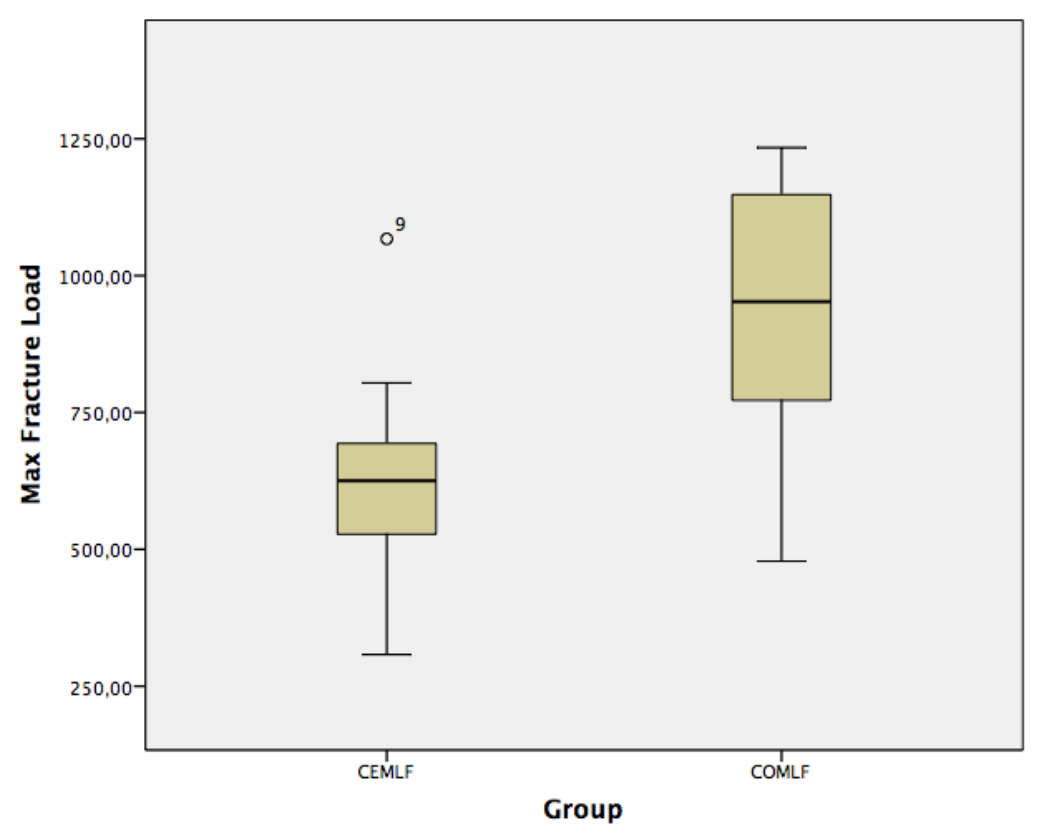

Fig. 5. Boxplot of the maximum load to failure data of groups CEMLF and COMLF.

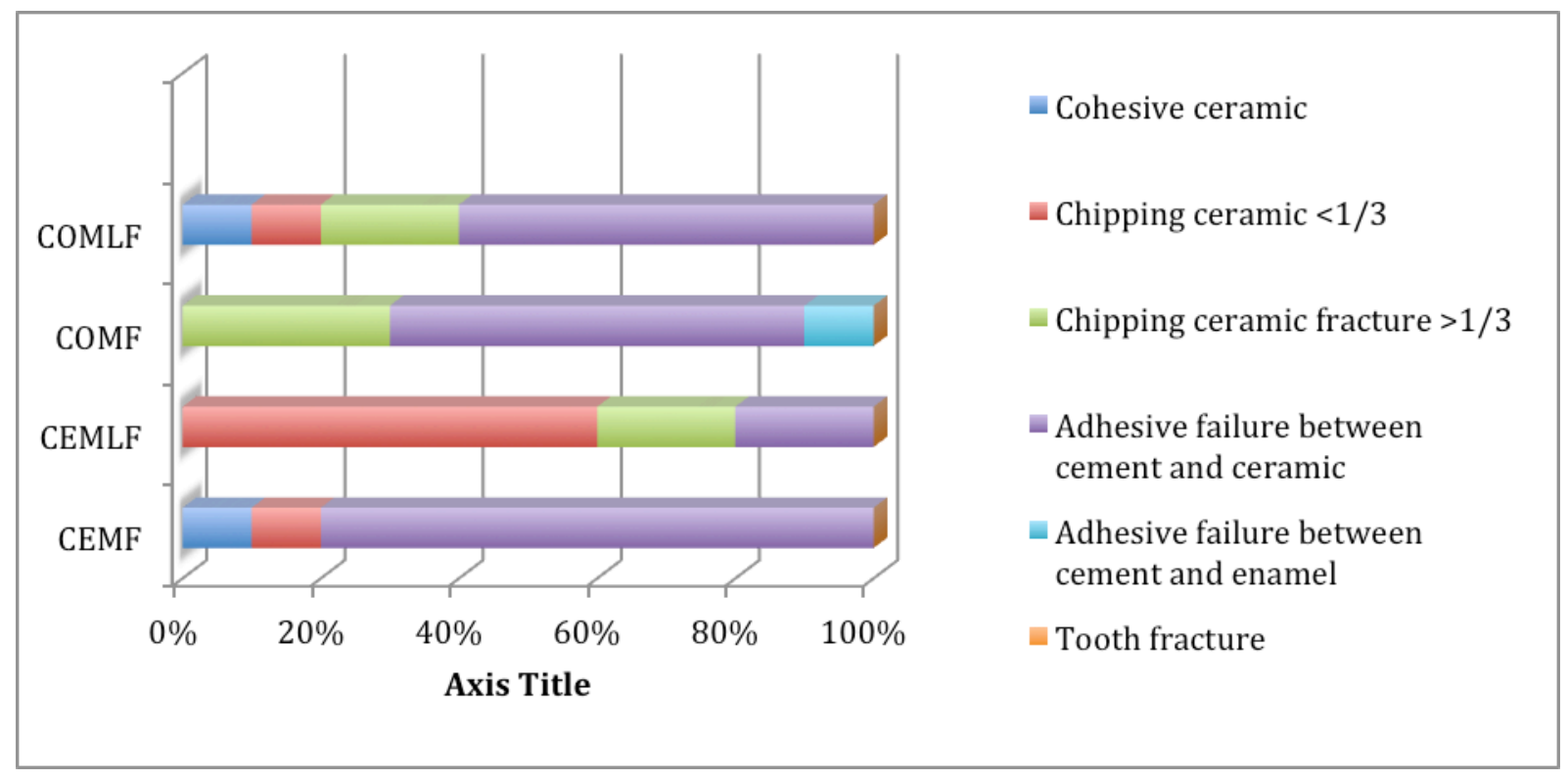

Fig. 6. Frequencies of failure modes in percentages. Type I: Cohesive ceramic fracture; Type II: Chipping of the ceramic <1/3; Type III: Chipping of the ceramic >1/3; Type IV: Adhesive failure between cement and ceramic; Type V: Adhesive between cement and enamel; Type VI: Tooth fracture. 

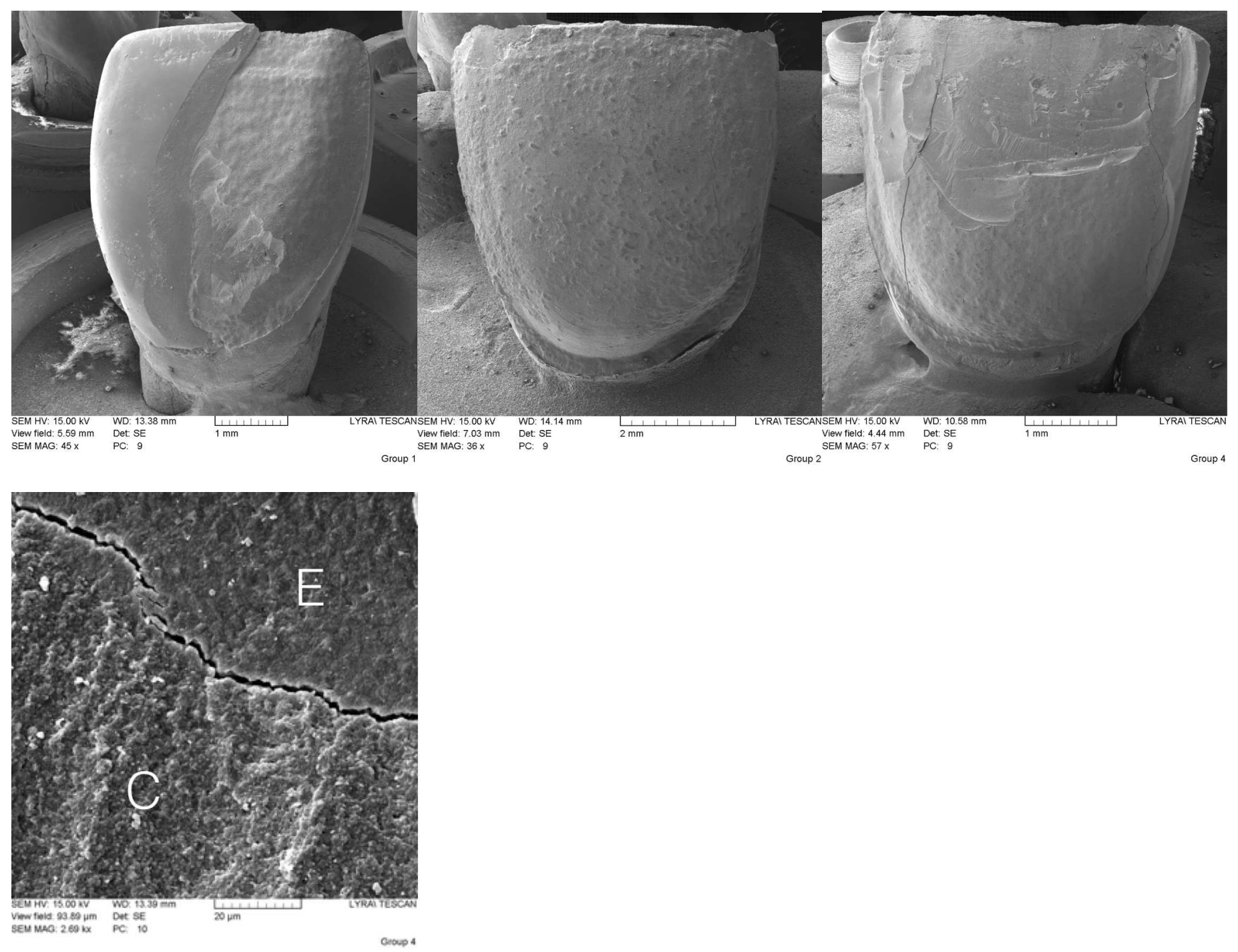

Figs. 7a-d. Typical failure types from a) a specimen in Group CEMLF where a chipping occurred in $>1 / 3$ of the laminate veneer, b) a specimen from group CEMF where delamination occurred between the ceramic and resin cement, c) a specimen from group COMF where an adhesive failure occurred between the resin cement and enamel, d) the corresponding SEM image (x 2500) of group COMF of the enamel $(E)$ and resin composite $(\mathrm{C})$ fracture. 